\title{
Interference with Activator Protein-2 transcription factors leads to induction of apoptosis and an increase in chemo- and radiation-sensitivity in breast cancer cells
}

Verena Thewes ${ }^{1,6+}$, Francesca Orso ${ }^{2,3 \dagger}$, Richard Jäger ${ }^{1,7}$, Dawid Eckert ${ }^{1}$, Sabine Schäfer ${ }^{1}$, Gregor Kirfel ${ }^{4}$, Stephan Garbe ${ }^{5}$, Daniela Taverna ${ }^{2,3}$, Hubert Schorle ${ }^{1 *}$

\begin{abstract}
Background: Activator Protein-2 (AP-2) transcription factors are critically involved in a variety of fundamental cellular processes such as proliferation, differentiation and apoptosis and have also been implicated in carcinogenesis. Expression of the family members AP- $2 \alpha$ and AP- $2 \gamma$ is particularly well documented in malignancies of the female breast. Despite increasing evaluation of single AP-2 isoforms in mammary tumors the functional role of concerted expression of multiple AP-2 isoforms in breast cancer remains to be elucidated. AP-2 proteins can form homo- or heterodimers, and there is growing evidence that the net effect whether a cell will proliferate, undergo apoptosis or differentiate is partly dependent on the balance between different AP-2 isoforms.
\end{abstract}

Methods: We simultaneously interfered with all AP-2 isoforms expressed in ErbB-2-positive murine N202.1 A breast cancer cells by conditionally over-expressing a dominant-negative AP-2 mutant.

Results: We show that interference with AP-2 protein function lead to reduced cell number, induced apoptosis and increased chemo- and radiation-sensitivity. Analysis of global gene expression changes upon interference with AP-2 proteins identified 139 modulated genes (90 up-regulated, 49 down-regulated) compared with control cells. Gene Ontology (GO) investigations for these genes revealed Cell Death and Cell Adhesion and Migration as the main functional categories including 25 and 12 genes, respectively. By using information obtained from Ingenuity Pathway Analysis Systems we were able to present proven or potential connections between AP-2 regulated genes involved in cell death and response to chemo- and radiation therapy, (i.e. Ctgf, Nrp1, Tnfaip3, Gsta3) and AP-2 and other main apoptosis players and to create a unique network.

Conclusions: Expression of AP-2 transcription factors in breast cancer cells supports proliferation and contributes to chemo- and radiation-resistance of tumor cells by impairing the ability to induce apoptosis. Therefore, interference with AP-2 function could increase the sensitivity of tumor cells towards therapeutic intervention.

\section{Background}

The familiy of Activator Proteins-2 (AP-2, Tcfap2) comprises 5 highly conserved DNA-binding transcription factors referred to as AP- $2 \alpha, \mathrm{AP}-2 \beta, \mathrm{AP}-2 \gamma, \mathrm{AP}-2 \delta$ and AP- $2 \varepsilon$ (or Tcfap2a-e) [1]. They preferentially bind GCrich consensus-sequences in their target genes, which

\footnotetext{
* Correspondence: hubert.schorle@ukb.uni-bonn.de

† Contributed equally

'Department of Developmental Pathology, Institute of Pathology, University of Bonn, Medical School, Germany
}

(c) 2010 Thewes et al; licensee BioMed Central Ltd. This is an Open Access article distributed under the terms of the Creative Commons Attribution License (http://creativecommons.org/licenses/by/2.0), which permits unrestricted use, distribution, and reproduction in any medium, provided the original work is properly cited.

results in transcriptional regulation either as a stimulatory or repressive event $[1,2]$. All AP-2 proteins share a modular protein structure consisting of a proline/glutamine-rich transactivation domain at the amino terminus, followed by a highly conserved central basic region and a helix-span-helix motif at the carboxyl terminus. DNA-binding is mediated by the basic region and requires dimer formation of two AP-2 proteins via the helix-span-helix motifs. AP-2 proteins are involved in manifold cellular functions such as proliferation, 
differentiation and apoptosis and play pivotal roles during embryonic development and carcinogenesis [1]. Especially the family members AP $-2 \alpha$ and AP- $2 \gamma$ have been implicated in breast cancer [3]. Under physiological conditions expression of AP $-2 \alpha$ and AP $-2 \gamma$ is restricted to either the luminal or the myoepithelial compartment in the breast, respectively $[4,5]$. In contrast simultaneous overexpression of AP $-2 \alpha$ and AP $-2 \gamma$ has been observed in breast carcinoma [4], but their impact on mammary tumorigenesis is still discussed controversially [6].

Several studies propose a tumor-suppressive function for AP-2 $\alpha$ in breast tissue [7-9] and data from clinical trials indicate that tumor progression is accompanied by loss of AP- $2 \alpha$ expression [10]. Moreover, loss of heterozygosity on chromosome position $6 \mathrm{p} 22$, where AP- $2 \alpha$ is mapped to, is frequently observed in breast cancer specimens [11]. Accordingly, high expression of AP-2 $\alpha$ in invasive breast cancer is correlated with favorable overall survival rates in patients [4].

Furthermore, in transgenic mouse studies, overexpression of AP- $2 \alpha$ in the mammary epithelium resulted in impaired mammary gland growth caused by a reduction in proliferation and a simultaneous increase in apoptosis [12]. This fits in vitro data where loss of AP- $2 \alpha$ lead to a decrease of apoptosis and an increased resistance towards chemotherapeutic drugs [8]. These effects might be partly mediated through control of expression of the CdK-Inhibitor p $21^{\mathrm{WAF}}$ and of p53 by AP- $2 \alpha$, which supports the idea that AP- $2 \alpha$ acts as a tumor suppressor $[9,13,14]$.

In contrast, little is known about the actual role of AP- $2 \gamma$ in breast carcinogenesis. Overexpression of AP$2 \gamma$ is frequently seen in breast tumors and breast cancer cell lines $[15,16]$ and has recently been shown to correlate with poorer response to hormone therapy and reduced patient survival in invasive breast cancer $[17,18]$. In addition, increased expression of AP- $2 \gamma$ has been associated with poorly differentiated breast tumor samples [4]. Gene amplification has been proposed as potential mechanism leading to overexpression of AP$2 \gamma$ because the gene maps to the genomic locus 20q13.2, which is frequently amplified in breast cancer [19]. Transgenic mouse studies provide further evidence for a role of AP- $2 \gamma$ in breast tumor formation: MMTV-driven overexpression of AP- $2 \gamma$ in the mammary epithelium leads to increase in proliferation and an impaired differentiation [20]. Moreover, bitransgenic mice expressing the oncogenic HER-2/neu receptor tyrosine kinase and AP- $2 \gamma$ showed an accelerated tumor progression compared to single-transgenic HER-2/neu mice [21]. Together, these findings point towards a causal involvement of AP- $2 \gamma$ in the etiology of breast cancer.
AP-2 proteins form either homo- or heterodimers [1]. There is evidence that under physiological conditions the net effect whether a cell proliferates, undergoes apoptosis or differentiates, may depend on the balance between different AP-2 isoforms [22]. So far, experiments addressing AP-2 functions in breast cancer cells were using either overexpression of, or interference with particular AP-2 isoforms. Overexpression of transcription factors may lead to occupancy of promoters not used under physiological conditions, which masks specific AP-2 functions. In the latter case, interference with a particular isoform may cause a shift in AP-2 dimer composition and hence obscure the physiological function.

In a complementary approach, we now set out to investigate the role of AP-2 proteins in a global manner by interfering with them functionally. To this end, we conditionally overexpressed a dominant-negative mutant $(\Delta \mathrm{AP}-2 \gamma)$ in the $\mathrm{N} 202.1 \mathrm{~A}$ murine breast cancer cell line expressing AP- $2 \alpha$ and AP- $2 \gamma$ endogenously. Interference with AP-2 proteins influenced the expression of genes involved in chemo- and radiation-sensitivity and resulted in the induction of apoptosis. These results establish an important role for AP-2 transcription factors in breast cancer cells determining their sensitivity towards chemotherapeutic agents and ionizing radiation. Expression of AP-2 proteins in breast tumors might therefore be of prognostic value. The results also suggest that AP-2 proteins or their target genes may be promising targets for therapeutic intervention in breast cancer.

\section{Methods \\ Plasmids}

pUHG172-1neo (rtTA) was kindly provided by H. Bujard (Heidelberg, Germany). In order to yield pBIEGFP, EGFP was cloned from pEGFP-C3 into pBI-4 (kindly provided by $\mathrm{H}$. Bujard (Heidelberg, Germany) as an NheI/XbaI fragment. $\triangle \mathrm{AP}-2 \gamma$ was created by deleting $474 \mathrm{bp}$ (158 aa of the $\mathrm{NH}$-terminus) of the 5 -portion of the murine AP- $2 \gamma$ cDNA. Upon introduction of a start codon using a NotI/NaeI-flanked oligo, $\Delta \mathrm{AP}-2 \gamma$ was cloned into pBIEGFP using NotI/Sal I restriction sites to generate pBIEGFP $\triangle \mathrm{AP}-2 \gamma$. The BMP-4 Firefly luciferase construct was kindly provided by M. Moser, (Martinsried, Germany) and the CMV-Renilla luciferase plasmid was obtained from Promega (Mannheim, Germany).

\section{Cell Lines and Cell Culture}

The murine breast cancer cell line N202.1A is derived from MMTV-HER-2/neu transgenic mice and was kindly provided by P.-L. Lollini (Bologna, Italy) [22]. N202.1A cells were grown in DMEM-Glutamax supplemented with $20 \%$ fetal calf serum and penicillin/streptomycin (Invitrogen, Karlsruhe, Germany). Cells were kept under standard conditions using a cell culture type 
incubator at $37^{\circ} \mathrm{C}$ under $7.5 \% \mathrm{CO}_{2}$. Functional assays were performed $96 \mathrm{~h}$ after addition of doxycycline to the cell culture media $(2 \mu \mathrm{g} / \mathrm{ml}$, BD Biosciences, Heidelberg, Germany).

\section{Transient and stable Transfection}

For stable transfection N202.1A cells were transfected using $39 \mu \mathrm{g}$ plasmid DNA (ratio plasmid - resistance gene 10: 1) using $107.5 \mu \mathrm{l}$ Lipofectamine 2000 (Invitrogen, Karlsruhe, Germany) per $10 \mathrm{~cm}$ culture dish according to the manufacturer's protocol. N202.1A cells

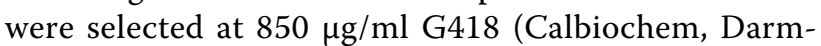
stadt, Germany) for the pUHG172-1neo and $200 \mu \mathrm{g} / \mathrm{ml}$ Hygromycin B (BD Biosciences, Heidelberg, Germany) for pBIEGFP $\triangle \mathrm{AP}-2 \gamma$ and pBIEGFP. For BMP-4 luciferase assays N202.1A cells were transfected with $900 \mathrm{ng}$ plasmid (870 ng BMP-4 Firefly luc +30 ng CMV-Renilla luc) and $1.75 \mu$ l Lipofectamine 2000 (Invitrogen, Mannheim, Germany) per 24 well culture dish according to the manufacturer's protocol.

\section{Microscopy and Image Processing}

Cells were visualized using a Leica-DM-IRB microscope (Bensheim, Germany), fitted to a Microfire digital camera (Optronics, Goleta, CA, USA) and image processing was performed applying Adobe Photoshop and Illustrator software.

\section{Co-Immunoprecipitation}

HCT116 cells were transfected with equal amounts of AP- $2 \alpha$ - and $\Delta$ AP- $2 \gamma$ - expression plasmids. Cells were lysed after 48 hours with non-denaturing lysis buffer. Co-IP was performed with $20 \mu$ DYNABEADS ${ }^{\oplus}$ (Invitrogen Cat.no. 199.03D, Invitrogen, Karlsruhe, Germany) und 1,5 $\mu$ g anti-AP-2 $\alpha$ antibody (H79, Santa Cruz, Heidelberg, Germany). $150 \mu \mathrm{g}$ protein lysate per sample was loaded. Western blot with anti-AP- $2 \gamma$ antibody (6E4/4, Santa Cruz, Heidelberg, Germany) followed.

\section{Western Blot Analysis, Luciferase Assays and Giemsa Staining}

Western Blot was performed using the following primary antibodies: AP-2 $\gamma$ (6E4/4, 1:200 Upstate, New York, USA), AP-2 $\alpha$ (H79, 1:200 Santa Cruz Heidelberg, Germany), AP-2 $\beta$ (1:1000), AP- $2 \delta$ (1:1500) and AP- $2 \varepsilon$ (1:1500), all kindly provided by M. Moser (Martinsried, Germany). The following secondary antibodies were used: goat anti-rabbit-HRP (1:2000 DAKO, Hamburg, Germany) and rabbit anti-mouse HRP (1:1000, DAKO, Hamburg, Germany). Protein lysates from HeLa (cervical carcinoma) N2A (neuroblastoma) cell lines and human keratinocytes or in vitro synthesized proteins, respectively, served as antibody positive controls for the different AP-2 isoforms in Western Blot analysis. BMP-
4 promoter luciferase assays were performed using the "Dual Luciferase Reporter Assay Systems Kit" (Promega, Mannheim, Germany) according to the manufacturer's protocol. $48 \mathrm{~h}$ upon induction $(2 \mu \mathrm{g} / \mathrm{ml}$ doxycycline $)$, N202.1A cells were transfected with BMP-4-Firefly luc, lysed, and luciferase activity was measured at $562 \mathrm{~nm}$ (Berthold Technologies, Bad Wildbad, Germany). Transfection efficiencies were normalized using a CMV-driven Renilla Luciferase (CMV-Renilla luc). To quantifiy cell numbers after treatment with chemotherapeutic compounds and irradiation cells were stained with Giemsa. For this purpose cells were washed twice in ice-cold PBS and fixed in methanol for $5 \mathrm{~min}$ at room temperature, stained for $5 \mathrm{~min}$ in Giemsa solution (Merck, Darmstadt, Germany) and washed gently in $\mathrm{H}_{2} \mathrm{O}$. Cells were quantified using ImageJ software (Adriamycin treatment) or three independent fields of visions were counted (irradiation) in each experiment.

\section{Proliferation}

Determination of S-phase index was carried out using the "Click-iT ${ }^{\mathrm{TM}}$ EdU Imaging Kit" (Invitrogen, Karlsruhe, Germany) according to the manufacturer's instructions. Briefly, $96 \mathrm{~h}$ after addition of doxycycline $(2 \mu \mathrm{g} / \mathrm{ml})$ N202.1A cells were incubated with $100 \mu \mathrm{M}$ thymidine analogon $\mathrm{EdU}$ for $30 \mathrm{~min}$ at $37^{\circ} \mathrm{C}$, fixed in $3.7 \%$ formaldehyde for $15 \mathrm{~min}$ and washed twice in $3 \% \mathrm{BSA} / \mathrm{PBS}$. Permeabilization was achieved using $0.5 \%$ Triton X-100/ PBS for $20 \mathrm{~min}$ and cells were washed twice with $3 \%$ BSA/PBS. Subsequently, the fixed cells were incubated with the reaction cocktail containing Alexa Fluor ${ }^{\circledR} 594-$ azide for $30 \mathrm{~min}$ and washed with $3 \% \mathrm{BSA} / \mathrm{PBS}$. Imaging using a Leica DM-IRB (Leica, Bensheim, Germany) microscope was followed by quantification of Edu Alexa Fluor ${ }^{\oplus 94}$-azide staining in three fields of vision (magnification $\times 100$ ) in three independent experiments. On average, a field of vision contained 218 cells.

\section{Transmission (TEM) - and scanning electron microscopy (SEM)}

For TEM-analysis, cells were fixed in $1.25 \%$ glutaralaldehyde in $0.1 \mathrm{M}$ cacodylate buffer $(\mathrm{pH} 7.4)$ for $1 \mathrm{~h}$ and post-fixed in $2 \% \mathrm{OsO}_{4}$ in cacodylate. Following dehydration in a graded series of ethanol, the specimens were embedded in a propylene-epon-mixture, mounted as $50 \mathrm{~nm}$ thin sections and post-contrasted with 3.5\% uranylacetate. TEM analysis was performed using a CM10 microscope (Philips, Eindhoven, Netherland).

For SEM cells were fixed in $2 \%$ glutaralaldehyde in $0.1 \mathrm{M}$ sodium cacodylate $(\mathrm{pH} 7.3)$ for $20 \mathrm{~min}$, transferred to $0.1 \%$ aqueous tannic acid and rinsed with distilled water. All specimens were dehydrated through a graded series of ethanol and critical pointdried from $\mathrm{CO}_{2}$ in 10 cycles using a Balzers CPD 030 
(BAL-TEC, Schalksmuehlen, Germany). Dried specimens were mounted on aluminium sample holders and coated with a $2 \mathrm{~nm}$ layer of platinum/palladium in a HE 208 sputter coating device (Cressington, Watford, UK). SEM analyis was performed with an XL 30 SFEG (Philips, Eindhoven, Netherlands).

\section{Caspase 3/7 Acitivity and AnnexinVC3.18 staining}

Caspase 3/7 activity was quantified using the "CaspaseGlo ${ }^{\oplus}$ 3/7 Assay Kit” (Promega, Mannheim, Germany) according to manufacturer's instructions. Non-induced or cells induced with doxycycline $(2 \mu \mathrm{g} / \mathrm{ml})$ for $96 \mathrm{~h}$ were incubated with "Caspase-Glo ${ }^{\oplus} / 7$ Reagent" for $3 \mathrm{~h}$ followed by measurement of luminescence at $562 \mathrm{~nm}$ (Berthold Technologies, Bad Wildbad, Germany). AnnexinVC3.18 staining was carried out using the "AnnexinVC.18 Kit" (Sigma-Aldrich, Munich, Germany). Doxycycline-induced cells were washed 3 times in PBS followed by 3 cycles of binding buffer for $1 \mathrm{~min}$. In the next step cells were incubated with the AnnexinVC3.18 conjugate (AnnexinVC3.18:binding buffer, 1:100) for $10 \mathrm{~min}$ at room temperature, washed 3 times in binding buffer and then subjected to fluorescence microscopy. Cells treated for $2.5 \mathrm{~h}$ with Staurosporine $(2 \mu \mathrm{M})$ served as positive controls (Sigma-Aldrich, Munich, Germany).

\section{Irradiation}

The irradiation of the N202.1 cells $96 \mathrm{~h}$ after addition of doxycyline $(2 \mu \mathrm{g} / \mathrm{ml})$ at $105 \mathrm{~Gy}$ was performed using a linear accelerator (Siemens Mevaton MD2, Siemens Medizintechnik, Munich, Germany). The photon energy of $6 \mathrm{MeV}$ at a dose rate of $2 \mathrm{~Gy} / \mathrm{min}$ was chosen. The field size was set to $20 \mathrm{~cm} \times 20 \mathrm{~cm}$ at a SSD (skin to surface distance) of $100 \mathrm{~cm}$. The beam divergence was approx. $11^{\circ}$. The cells were irradiated in a 6 -well plate using a RW3-Phantom (PTW) at dose maximum. The photon beam was calibrated according the DIN 6800-2 protocol for a water equivalent energy dose. The RBWfactor for $6 \mathrm{MeV}$ irradiation is almost 1, so the energy dose was equivalent to the biological dose.

\section{RNA isolation and qRT-PCR}

Total RNA was isolated from the various clones using Trizol Reagent (Invitrogen, Karlsruhe, Germany) according to the manufacturer's instructions. $1 \mu \mathrm{g}$ of DNase-treated (DNA-free $^{\mathrm{TM}}$ kit, Ambion, Austin, TX) total RNA was reverse transcribed using RETROscript ${ }^{\mathrm{TM}}$ reagents (Ambion, Austin, TX). RNA was heat-denatured for 3' at $85^{\circ} \mathrm{C}$ and the reaction was incubated at $42^{\circ} \mathrm{C}$ for 1 hour and $10^{\prime}$ at $92^{\circ} \mathrm{C}$. Quantitative Real Time PCR (qRT-PCR) reactions were carried out in 96 well plates using SYBRGreen ${ }^{\circledR}$ Master Mix (Applied Biosystems, Foster City, CA), specific primers and $10 \mathrm{ng}$ total RNA converted into cDNA in $10 \mu \mathrm{l}$ final volume. Fluorescence was measured using an ABI Prism ${ }^{\circledR} 7300$ (Applied Biosystems, Foster City, CA) detection system according to the manufacturer's instructions. Primers were purchased from QIAGEN (QuantiTect ${ }^{\oplus}$ Primer Assays). Relative quantitations to control cells were performed: first, each $\mathrm{Ct}$ value was corrected for the $\mathrm{Ct}_{\mathrm{r}}$ of the reference gene, GAPDH, and then the $\mathrm{Ct}$ of each sample was subtracted from the $\mathrm{Ct}$ of control cells $\left(\mathrm{Ct}_{0}\right)$. The relative amount of template $(\mathrm{Q})$ was therefore calculated as: $\mathrm{Q}=2^{-\left(\mathrm{Ct}-\mathrm{Ct}_{\mathrm{r}}\right)-\left(\mathrm{Ct}_{0}-\mathrm{Ct}_{0} \mathrm{r}\right)}$. All samples were run in triplicates and mean and standard deviation calculated as described in Bookout et al. 2003 [23]. QuantiTect ${ }^{\oplus}$ Primer Assay catalogue numbers are as follows: QT00101297 Mm_Tcfap2c_1_SG QuantiTect Primer Assay (200) (NM_009335, NM_001159696); QT00265524 Mm_Egr3_1_SG QuantiTect Primer Assay (200) (NM_018781); QT00096131 Mm_Ctgf_1_SG QuantiTect Primer Assay (200) (NM_010217); QT01044295 Mm_Sema3b_1_SG QuantiTect Primer Assay (200) (NM_009153); QT00157381 Mm_Nrp1_1_SG QuantiTect Primer Assay (200) (NM_008737); QT01061599 Mm_Gsta3_1_SG QuantiTect Primer Assay (200) (NM_010356); QT00100653 Mm_Gzme_1_SG QuantiTect Primer Assay (200) (NM_010373); QT00134064 Mm_Tnfaip3_1_SG QuantiTect Primer Assay (200) (NM_009397). QT00105483 Mm_Fst_1_SG QuantiTect Primer Assay (200) (NM_008046).

\section{Northern Blot}

Northern Blot analysis was carried out as described in Jäger et al. [20] using the murine AP- $2 \gamma \mathrm{cDNA}$ as a probe.

\section{Whole genome expression analysis}

Microarray analysis of gene expression in response to expression of $\triangle \mathrm{AP}-2 \gamma / \mathrm{EGFP}(\Delta \# 7+\Delta \# 15)$ or EGFP $(\Delta \# 5+\Delta \# 11)$ in $\mathrm{N} 202.1 \mathrm{~A}$ breast cancer clones $(2 \mu \mathrm{g} / \mathrm{ml}$ doxycyline for $96 \mathrm{~h}$ ) was performed using the Illumina BeadChip system (Illumina, Inc, San Diego, CA). We used $500 \mathrm{ng}$ of total RNA to obtain labeled, amplified cRNA for each sample to hybridize the Illumina Ref-8 BeadChips according to manufacturer's instructions (Illumina, Inc, San Diego, CA). Arrays were scanned with an IlluminaBeadArray Reader confocal scanner and data processed and analyzed using IlluminaBeadStudio software (Illumina, Inc, San Diego, CA). Raw Illumina data were rank invariant normalized with BeadStudio software (Illumina, Inc, San Diego, CA), which was also used to assess differential expression between the $\triangle \mathrm{AP}$ $2 \gamma$ and control clones, based on three RNA preparations from each clone after subtraction of the background obtained with control clones following doxycyclin treatment. After normalization, genes were filtered by their 'detection' value, which had to be 0.99 (significantly detected), in the three samples. Subsequently, we 
identified differentially expressed genes using the Illumina custom error model implemented in BeadStudio, which provides an expression difference score ('DiffScore') taking into account background noise and sample variability [24]. We chose a DiffScore threshold of 30 , corresponding to a $\mathrm{p}$ value of 0.001 , with a False Discovery Rate (FDR) lower than $5 \%$. To restrict the analysis to the most regulated genes, an additional filtering criterion was that the average expression foldchange between $\Delta \mathrm{AP}-2 \gamma / \mathrm{EGFP}-(\Delta \# 7$ or $\Delta \# 15)$ and EGFP- $(\Delta \# 5$ or $\Delta \# 11)$ expressing clones had to be at least 1.5 -fold, which lead to the identification of 139 modulated transcripts (49 decreased and 90 increased). Sample permutation analysis confirmed that under these conditions the FDR was well below $5 \%$.

\section{Gene Set Enrichment Analysis}

Gene Set Enrichment Analysis (GSEA) is a computational method used to look for overlaps between the AP-2-driven gene set obtained from the microarray analysis and modulated genes present in the Molecular Signature Database (MSigDB) following chemical and genetic perturbations [25].

\section{Chromatin immunoprecipitation (ChIP) assays}

ChIP was performed using the ChIP-IT ${ }^{\mathrm{TM}}$ Kit (Active Motif, Carlsbad, CA) reagents and protocols. Primer pairs were designed on the TFAP2 binding site containing regions (identified by TRANSFAC) using the Primer-BLAST software http://www.ncbi.nlm.nih.gov/tools/ primer-blast/index.cgi?LINK_LOC=NcbiHomeAd. The following primers were used: Tnfaip3FW: 5'CCCCTAACGGAGGCACTCTTCCAC-3'; Tnfaip3RV: 5'-CCGCCTCCTCCAGGTCTTCCTAGCCC-3'; Ctgf FW: 5'-AGGAAGTCTC GGGCCTCTTCTCTTTGA-3'; CtgfRV: 5'-TCAAGTGGCTGACCACATCATCTG CAC-3'.

PCR was performed using Platinum ${ }^{\circledast}$ Taq DNA Polymerase according to the manufacturer's instructions.

\section{Results}

Establishment of N202.1A breast cancer cells conditionally expressing $\triangle \mathrm{AP}-2 \gamma$ using the Tet-ON ${ }^{\circledR}$ System

To assess the role of AP-2 proteins in breast cancer we took advantage of the murine N202.1A breast cancer cell line [26], which had been derived from a mammary tumor of a MMTV-HER-2/neu transgenic mouse and expresses AP- $2 \alpha$ and AP- $2 \gamma$. To functionally interfere with AP-2 proteins, we constructed a dominant-negative mutant of the transcription factor AP-2 (Figure 1A). For this purpose we used a truncated $\mathrm{CDNA}$ of the murine AP- $2 \gamma$ lacking the 5'-portion, which encodes the 158 amino acids of the transactivation domain. This mutant, referred to as $\Delta \mathrm{AP}-2 \gamma$ (Figure $1 \mathrm{~B}$ ), is still able to dimerize but fails to regulate target genes due to the lack of its transactivation domain. It therefore interferes with AP-2 function in a dominant-negative manner [27,28]. Conditional expression of the $\Delta \mathrm{AP}-2 \gamma$ construct was achieved using the Tet- $\mathrm{ON}^{\circledast}$ System with a bidirectional promoter allowing for simultaneous expression of the dominant-negative AP- $2 \gamma$ molecule $(\Delta \mathrm{AP}-2 \gamma)$ and the reporter Enhanced Green Fluorescent Protein (EGFP, Figure 1C) in a doxycycline-dependent manner (Figure 1D). Stable transfection of N202.1A cells with these constructs yielded clones conditionally coexpressing the $\triangle \mathrm{AP}-2 \gamma$ and EGFP upon addition of doxycycline (Figure 1E, G compare to inset). To exclude clonal effects due to different copy numbers or integration sites of the transfected constructs all analyses were performed with two independently derived clones $(\Delta \# 7$, $\Delta \# 15)$. Furthermore we created control clones, conditionally expressing only EGFP (Co\#5, Co\#11), in order to exclude unspecific effects caused by EGFP expression or by doxycycline treatment (Figure $1 \mathrm{~F}, \mathrm{H}$, compare to inset).

Western blot analyses demonstrated the expression of AP $-2 \alpha$ and little amounts AP- $2 \delta$ in N202.1A cells (Figure 2A). Subsequent northern- and western blot analyses showed expression of AP- $2 \gamma$ in the cells and further documented, that the clones strongly overexpress $\triangle \mathrm{AP}-2 \gamma$ both on RNA and on protein level after addition of doxycycline. Of note, no band indicative of expression of $\triangle \mathrm{AP}-2 \gamma$ could be detected in the absence of doxycline. Also, expression of $\triangle \mathrm{AP}-2 \gamma$ did not affect the level of endogenous AP- $2 \gamma$ (Figure 2B, C). Using CoIP we demonstrated the ability of the truncated $\triangle \mathrm{AP}$ $2 \gamma$ molecule to heterodimerize with AP- $2 \alpha$ as well (Figure 2D). To confirm the functionality of $\Delta \mathrm{AP}-2 \gamma$, we performed a luciferase reporter assay using a BMP-4 promoter element. BMP-4 expression is modulated by AP-2 transcription factors (unpublished data). The expression of $\triangle \mathrm{AP}-2 \gamma$ significantly reduced the luciferase signal in the $\triangle \mathrm{AP}-2 \gamma(\mathrm{P}<0.01)$ clones but not in controls (Figure 2E). Therefore we have established a system which allows for functional interference with AP-2 transcription factors in N202.1A mammary tumor cells.

\section{Whole genome expression analysis and target gene identification}

To better understand the role of AP-2 transcription factors in initiation and progression of breast cancer, we set out to identify AP-2 regulated genes using whole genome expression analysis. The global patterns of gene expression were analyzed in $\triangle \mathrm{AP}-2 \gamma$ expressing (\#7 and \#15) clones versus control (\#5 and \#11) clones in presence of doxycycline. In total 139 differentially expressed 
A AP-2 $\gamma$

\begin{tabular}{|c|c|c|}
\hline $\mathrm{NH} 2$ & & \\
\hline PY & Basic & Helix-Span-Helix \\
\hline Transactivation & & Dimerisation \\
\hline
\end{tabular}

DNA-Binding

B $\Delta$ AP-2 $\gamma$

Basic Helix-Span-Helix

C

- dox

\begin{tabular}{|c|c|c|c|c|}
\hline$\triangle A P-2 \gamma$ & CMV & TRE & CMV & EGFP \\
\hline
\end{tabular}

rtTA

D
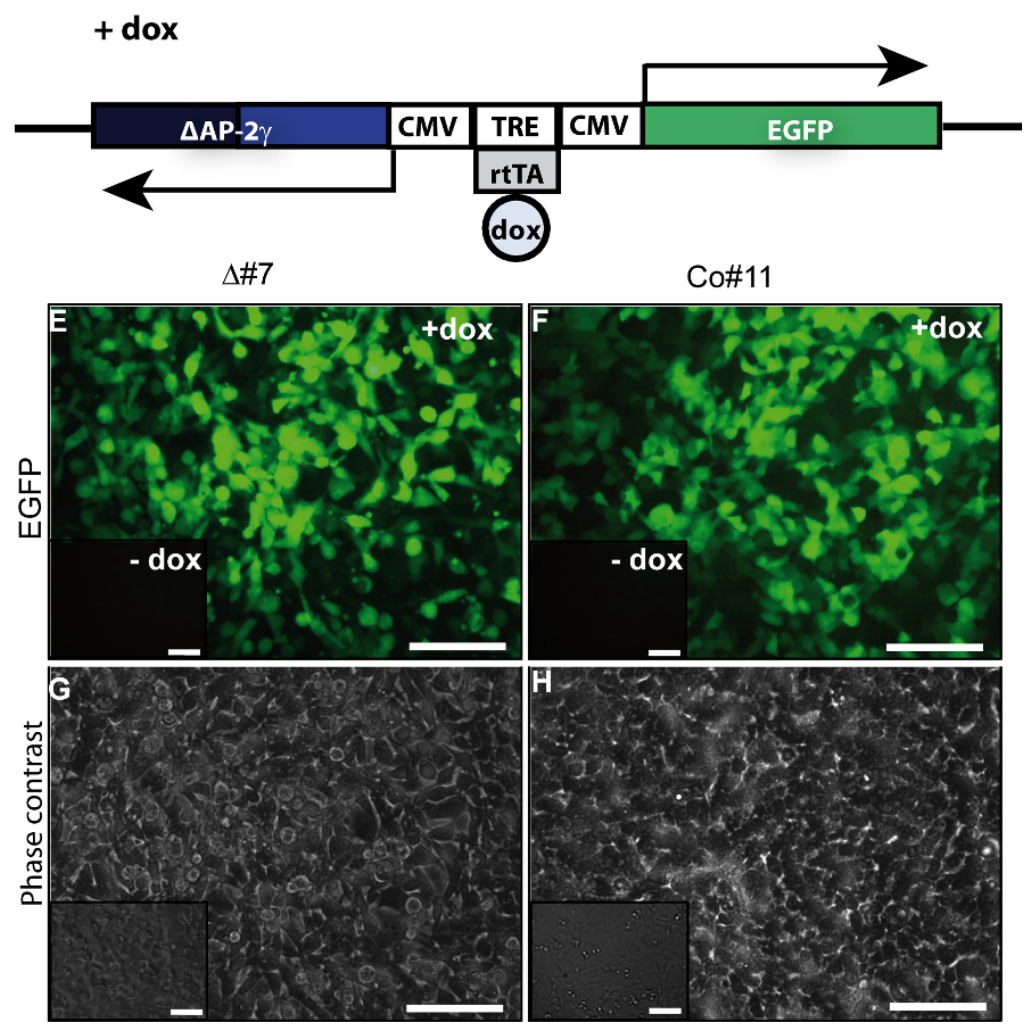

Figure 1 Establishment of the conditional $\triangle \mathrm{AP}-2 \gamma$ expression system using the Tet-ON ${ }^{\circledR}$ System in N202.1A breast cancer cells. (A) The schematic representation of the structural AP-2 protein domains shows the $\mathrm{N}^{\prime}$-terminal proline- and glutamine-rich (PY) transactivation domain, the DNA-binding domain which consists of the basic region and the helix-span-helix motif and the C'-terminal dimerization domain. (B) The dominant-negative AP- $2 \gamma$ mutant $(\triangle \mathrm{AP}-2 \gamma)$ has a deleted transactivation domain and therefore an abolished transactivation potential. It still dimerizes with full length AP-2 proteins, thereby inhibiting their function. (C, D) Usage of a bidirectional Tet Responsive Element promoter (TRE) allowed for conditional coexpression of $\triangle \mathrm{AP}-2 \gamma$ and EGFP upon addition of doxycycline (+dox, $2 \mu \mathrm{g} / \mathrm{ml}$ ) in rtTA containing N202.1A cells. (E-H) Generation of N202.1A clones expressing $\triangle A P-2 \gamma$ and/or EGFP respectively: stably transfected N202.1A rtTA breast cancer cells were screened for conditional expression of rtTA and either $\triangle A P-2 \gamma$ and EGFP $(E, \triangle \# 7)$ or EGFP only $(F, C o \# 11)$ using fluorescence $(E, F)$ and phase contrast $(G, H)$ microscopy. Clones display a low backround expression in the uninduced state (-dox) but high transgene expression upon induction (+dox, $2 \mu \mathrm{g} / \mathrm{ml})$. Scale Bar in E-H represents $50 \mu \mathrm{m}$. 


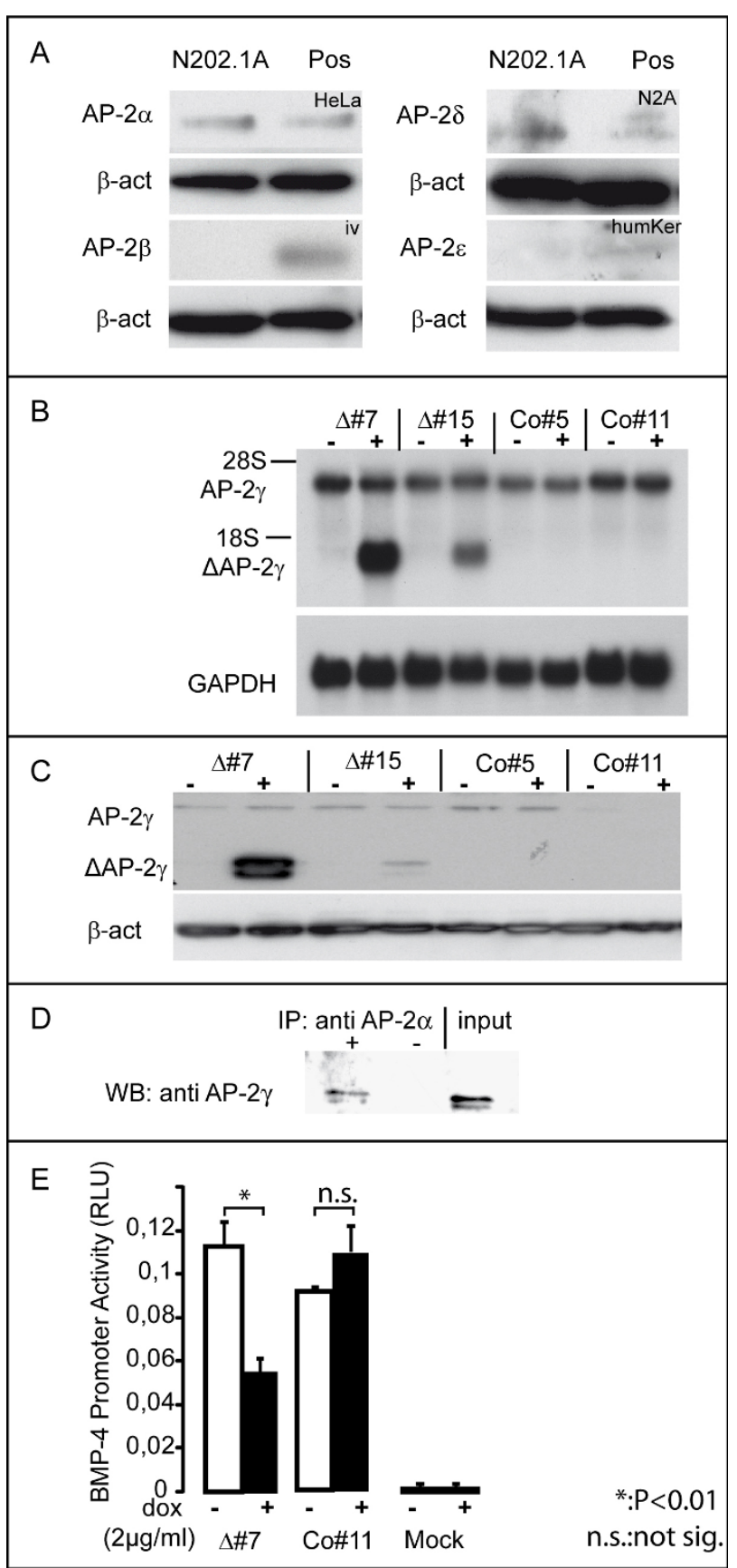

Figure 2 AP-2 isoform and conditional $\triangle \mathrm{AP}-2 \gamma$ expression in N202.1A cells. Verification of $\Delta \mathrm{AP}-2 \gamma$ function using BMP-4 luciferase promoter assays. (A) Western-blot using antibodies detecting the different AP-2 isoforms in N202.1A cells. As positive control (Pos) for the antibodies, we used protein lysate from HeLa cells for AP-2 $\alpha$ (HeLa), N2A cells for AP- $2 \delta$ (N2A), human Keratinocytes for AP- $2 \varepsilon$ (hum Ker) and in vitro translated protein for AP-2 $\beta$ (iv). (B) Northern blot analysis of $\triangle A P-2 \gamma$ expression in the stable N202.1A clones, uninduced or induced with doxycycline $(2 \mu \mathrm{g} / \mathrm{ml})$. Fifteen micrograms of total RNA were resolved on a formaldehyde gel, transferred to a Nylon membrane and hybridized with a P-32-labelled AP-2 $\gamma$ CDNA probe. GAPDH probe was used to monitor the amounts of RNA. (C) N202.1A cells were induced with doxycycline $(2 \mu \mathrm{g} / \mathrm{ml})$ for $96 \mathrm{~h}$ and subjected to western blot analysis. $\Delta \# 7$ and $\Delta \# 15$ show strong transgene expression in a doxycyline dependent-manner $(32 \mathrm{kDa}$ ), which is not detectable in Co\#5 and Co\#11. Of note, the antibody also detects endogeneous AP-2 $\gamma$ (50 kDa) which is not affected by doxycycline. (D) HCT116 cells were transfected with expression constructs for AP-2 $\alpha$ and $\triangle A P-2 \gamma$. Co-IP experiment using antibody to AP- $2 \gamma$ for IP and antibody to AP- $2 \alpha$ to detect heterodimerization between $\triangle$ AP- $2 \gamma$ and AP-2 $\alpha$. - no Antibody; + IP using AP- $2 \gamma$ Antibody; input control. (E) For BMP-4-promoter luciferase assays N202.1A cells were induced with doxycycline for $96 \mathrm{~h}$ and transfected with BMP-4 luciferase. $48 \mathrm{~h}$ after transfection luciferase activity was quantified. For internal normalization of transfection efficiency a CMV-driven renilla luciferase was used. 
genes were found. In order to correlate gene expression to promoter occupancy, the promoter regions of 96 genes were analyzed using Transfac analyses to define consensus binding sites for AP-2 proteins. Of these 96 candidate genes, 52 genes displayed AP-2 binding sites indicating a direct regulation (additional file 1: Table S1). Sequence alignments revealed, that 23 of the 52 binding sites are conserved between mouse and human, further suggesting a functional role for AP-2 in regulating these genes. (additional file 1: Table $\mathrm{S} 1$, genes marked in red). To investigate whether AP-2 transcription factors directly bind to these target genes 'in vivo' chromatin immunoprecipitation was performed on promoter elements of Connective Tissue Growth Factor (Ctgf) and Tumor necrosis factor alpha-induced protein 3 (Tnfaip3). Both AP $-2 \alpha$ and AP $-2 \gamma$ are recruited to promoter regions of these genes, confirming a direct regulation (Figure 3A). Differentially expressed genes were distributed in different Gene Ontology (GO) classes, the main one being cell death (25 genes), followed by cell adhesion and cell movement (12 genes), and nucleosome assembly (8 genes). In particular, several cell death players were found and listed in Table 1. Among them Connective Tissue Growth Factor (Ctgf), Neuropilin1 (Nrp1), Chemokine C-C motif ligand 9 (Ccl9) and Tumor necrosis factor alpha-induced protein 3 (Tnfaip3) were highly up-regulated suggesting a repressive role of AP-2 on these genes. On the other hand Semaphorin $3 B$ (Sema3b) and Early Growth Response 3 (Egr3) were strongly down-regulated suggesting an activating function of AP-2 on these genes. Microarray data were validated by qRT-PCR performed on three different RNA preparations for each clone for 6 genes involved in cell death and for 3 genes belonging to other GO classes, all showing a fold change (FC) $>2.0$ (Figure3B). Differential gene expression obtained from microarray analysis was compared with data resulting from clones $\triangle \# 7$ and $\Delta \# 15$ versus $C o \# 5$ and $C o \# 11$ or from clone $\triangle \# 7$ versus Co\#11. Data were normalized using the GAPDH gene as internal control. Using some of the information obtained with Ingenuity ${ }^{\mathrm{TM}}$ Pathway Analysis Systems we were able to build a simplified network for genes involved in cell death (Figure 3C).

\section{Gene Set Enrichment Analysis}

By using the computational Gene Set Enrichment Analysis (GSEA) we looked for gene overlaps between our AP-2-dependent differentially expressed genes (additional file 1: Table 1) and a collection of twenty chemical and genetic perturbation gene datasets spanning 16,271 genes present in the Molecular Signature Database (MSigDB, http://www.broadinstitute.org/gsea/ msigdb/) [25]. Results are reported in additional file 2: Table 2, where we found that modulation of the AP-2 dependent genes, such as thrombospondin 1, tumor necrosis factor, alpha-induced protein 3, jagged 1, semaphorin 3 , early growth response3, anillin, collagen type $X$ alpha 1, hydroxysteroid(11-beta)dehydrogenase 1 have also been found in collections of up- or down-regulated genes following chemical and genetic perturbations. These findings reinforce the involvement of AP-2-driven genes with apoptosis and chemo- and radiationsensitivity.

Interference with AP-2 proteins increases the chemo- and radiation-sensitivity of $\mathrm{N} 202.1 \mathrm{~A}$ breast cancer cells

The global gene expression analysis also identified AP-2 regulated genes, which have an impact on sensitivity of cancer cells towards chemotherapeutic drugs and irradiation like for example the ATP-bindingcassette, subfamilyB (MDR/TAP) member 9 and GSTA3 (Figure 3B) [29,30]. Therefore we tested whether interference with AP-2 proteins has an influence on the chemo- and radiation-sensitivity of N202.1A breast cancer cells.

For this purpose the cells were induced with doxycycline for $96 \mathrm{~h}$ and then additionally treated with chemotherapeutic drugs. $72 \mathrm{~h}$ after treatment with the topoisomerase II inhibitor Adriamycin, the $\Delta \mathrm{AP}-2 \gamma$ expressing clones showed an apparent change in morphology; they displayed a more roundish morphology (Figure 4A) compared to the non-induced cells or control cells, which retained a healthy polygonal morphology. After $72 \mathrm{~h}$ the cell numbers had dropped to approximately $60 \%$ in the cultures where $\triangle \mathrm{AP}-2 \gamma$ was expressed compared to controls (Figure 4B) ( $\mathrm{p}=0.009)$. A similar trend was observed after treatment with Etoposide and Cisplatin (data not shown). These data indicate that repression of AP-2 protein function results in enhanced sensitivity towards chemotherapeutic drugs such as Adriamycin, Etoposide and Cisplatin.

Irradiation represents another main pillar to cure a tumor burden, so we addressed the question whether AP-2 expression impinges on the sensitivity of the cells towards ionizing radiaton. The $\triangle \mathrm{AP}-2 \gamma$ expressing clones displayed significantly (clone $\Delta \# 7: \mathrm{p}=0.0004$; clone $\Delta \# 15$ : $\mathrm{p}=0.0005)$ reduced cell numbers $72 \mathrm{~h}$ after irradiation with 105 Gray compared to controls, as revealed by Giemsa-staining (Figure 4A, C). Hence, repression of AP-2 function resulted in increased sensitivity towards ionizing radiation and we conclude that expression of AP-2 genes might confer a selective advantage to breast tumor cells towards chemotherapeutic agents and irradiation.

\section{Interference with AP-2 proteins causes a reduction in proliferation rate and leads to induction of apoptosis}

To address the question whether interference with AP-2 proteins had an influence on the proliferation rate of 


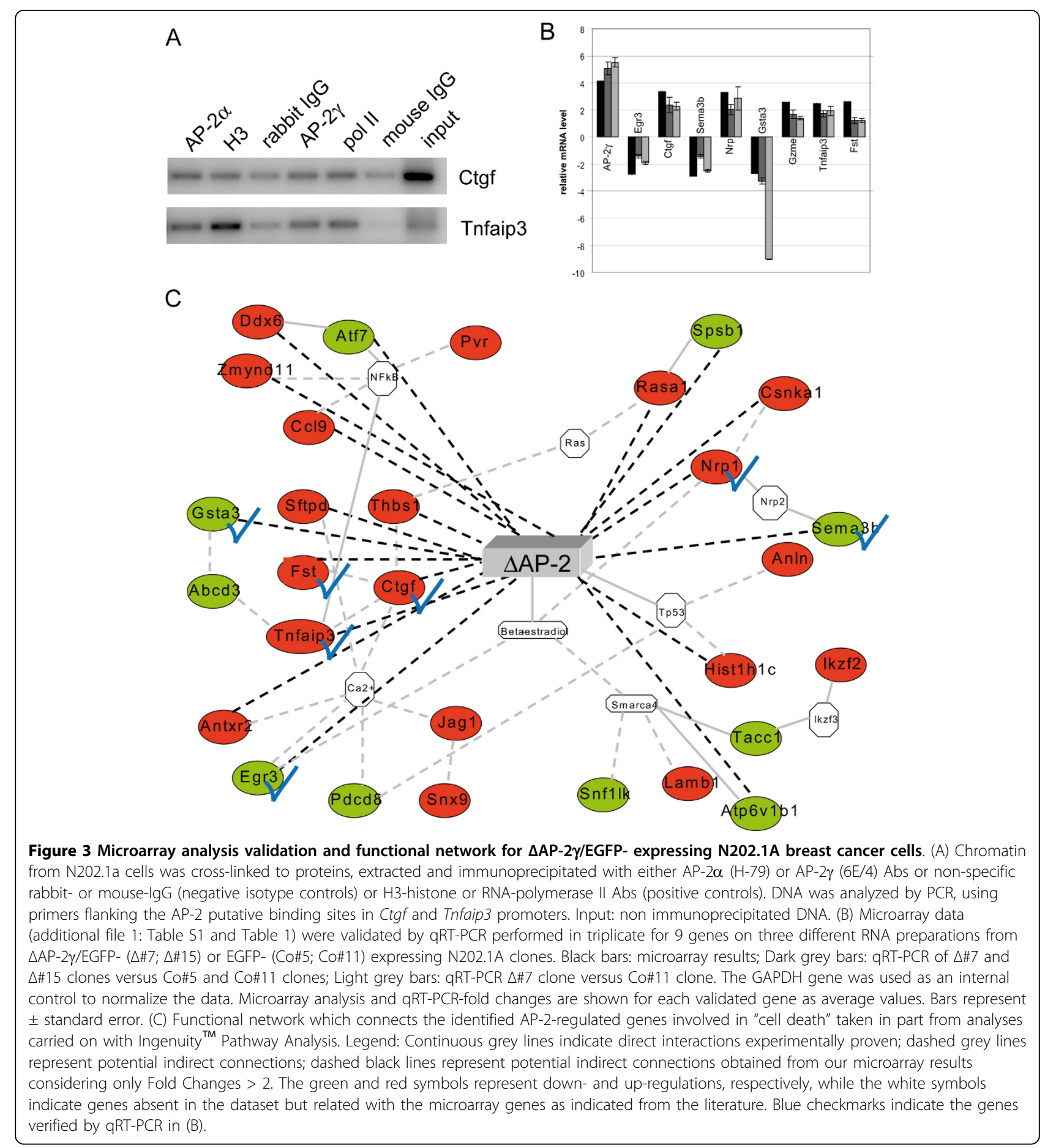

N202.1A breast cancer cells, we subjected them to "Click $\mathrm{iT}^{\mathrm{TM}}$ "(Invitrogen) assays which selectively stain cells in S-phase. We detected a decrease in proliferation rate of approximately $30 \%$ in clones expressing $\triangle \mathrm{AP}-2 \gamma$ compared to uninduced und control cells (Figure 5A). These results suggest that AP-2 proteins mediate proproliferative functions.
After interference with AP-2 transcription factors we observed changes in morphology of the N202.1A cells. After interference for 96 hrs small protrusions (blebs) on the plasma membrane could be detected (Figure 5B, arrow). These protrusions could be verified using Scanning (Figure 5D) and Transmission (Figure 5F) Electron Microscopy and were not seen in uninduced clones 
Table 1 Cell death-related genes in $\triangle$ AP-2 $\gamma /$ EGFP- expressingN202.1A cells

\begin{tabular}{|c|c|c|c|}
\hline Accession & Symbol & Definition & FC \\
\hline NM_010217 & Ctgf & connective tissue growth factor (Ctgf), mRNA. & 3,4 \\
\hline NM_008737.1 & Nrp & neuropilin (Nrp), mRNA. & 3,3 \\
\hline NM_011338 & Ccl9 & chemokine (C-C motif) ligand 9 (Ccl9), mRNA. & 3,3 \\
\hline NM_015786 & Hist1h1c & histone 1, H1c (Hist1h1c), mRNA. & 3,1 \\
\hline NM_009160.1 & Sftpd & surfactant associated protein D (Sftpd), mRNA. & 2,9 \\
\hline NM_008046.1 & Fst & follistatin (Fst), mRNA. & 2,6 \\
\hline AK031617 & Csnk2a1-rs3 & casein kinase $\|$, alpha 1 related sequence 3, mRNA & 2,5 \\
\hline NM_010762.2 & Mal & myelin and lymphocyte protein, T-cell differentiation protein (Mal), mRNA. & 2,5 \\
\hline NM_009397.2 & Tnfaip3 & tumor necrosis factor, alpha-induced protein 3 (Tnfaip3), mRNA. & 2,5 \\
\hline NM_011580.1 & Thbs1 & thrombospondin 1 (Thbs1), mRNA. & 2,3 \\
\hline NM_144516.1 & Zmynd11 & zinc finger, MYND domain containing 11, mRNA & 2,3 \\
\hline NM_080428 & Fbxw7 & F-box and WD-40 domain protein 7, archipelago homolog (Drosophila) (Fbxw7), mRNA. & 2,2 \\
\hline NM_145452 & Rasa1 & RAS p21 protein activator 1 (Rasa1), mRNA. & 2,1 \\
\hline NM_133853.1 & Magi3 & membrane associated guanlylate kinase, WW and PDZ domain containig 3 & 2,0 \\
\hline NM_133738 & Antxr2 & anthrax toxin receptor $2, \mathrm{mRNA}$ & 2,0 \\
\hline NM_028390.1 & Anln & anillin, actin binding protein (scraps homolog, Drosophila) (Anln), mRNA. & 1,9 \\
\hline NM_012019.2 & Pdcd8 & programmed cell death $8(\mathrm{Pdcd} 8)$, mRNA. & 1,9 \\
\hline NM_013822.2 & Jag1 & jagged 1 (Jag1), mRNA. & 1,8 \\
\hline NM_010789.1 & Meis1 & myeloid ecotropic viral integration site 1 (Meis1), mRNA. & 1,7 \\
\hline J05277.1 & $\mathrm{Hk} 1$ & hexokinase mRNA, complete cds. & $-2,0$ \\
\hline NM_177089.3 & Tacc1 & Transforming, acidic coiled coil protein 1 & $-2,0$ \\
\hline NM_010777.1 & Mbp & myelin basic protein (Mbp), mRNA. & 2,5 \\
\hline XM_483957 & Dyrk2 & dual-specificity tyrosine-(Y)-phosphorylation regulated kinase 2, mRNA & 2,5 \\
\hline NM_018781 & Egr3 & early growth response 3 (Egr3), mRNA. & $-2,7$ \\
\hline NM_009153.1 & Sema3b & $\begin{array}{l}\text { sema domain, immunoglobulin domain (lg), short basic domain, secreted, } \\
\text { (semaphorin) 3B (Sema3b), mRNA. }\end{array}$ & $-2,9$ \\
\hline
\end{tabular}

Microarray analysis (Illumina Ref-8 BeadChip) was performed on $\Delta$ AP-2 $\gamma(\Delta \# 7, \Delta \# 15)$ or EGFP- (Co\#5, Co\#11) expressing N202.1A clones in triplicate and 25 modulated genes involved in cell death ( 6 decreased, 19 increased, see Methods) were found. FC $=$ Fold change. $p<0.001 ; F C$. $+/-1.5$.

(data not shown) or controls (Figure 5C,E,G). To ascertain if the blebbing was based on changes in the actin cytoskeleton, actin fibers were stained with Phalloidin $96 \mathrm{~h}$ after addition of doxycycline. However, we could not detect structural changes of the actin cytosceleton (not shown). This suggests that vesicle formation upon interference with AP-2 function does not involve the modification of actin cytoskeleton structure.

We reasoned that the blebs caused by $\Delta \mathrm{AP}-2 \gamma$ expression might represent apoptotic bodies and therefore checked for other apoptotic markers. First, activity of Caspase 3/7 was measured as an early marker of apoptosis. Untreated clones were compared to doxycyclinetreated clones and Caspase 3/7 activity was quantified. Long-time interference with AP-2 function (96 hrs) resulted in a marked increase $(p=0.045$ for $\Delta \# 7)$ in Caspase $3 / 7$ activity compared to uninduced and control cells (Figure 6A). Furthermore, a fraction of cells expressing $\triangle \mathrm{AP}-2 \gamma$ were positive for AnnexinV3.18 staining (Figure 6B-G) which represents another indicator of apoptosis. The morphological changes caused by treatment with the apoptosis-inducer Staurosporine were similar to the blebbing seen upon expression of $\Delta \mathrm{AP}-2 \gamma$, suggesting that the $\triangle \mathrm{AP}-2 \gamma$ expressing cells indeed are undergoing apoptosis (Figure 6E-G, compare to 6B-D).

To summarize our findings, interference with AP-2 transcription factors in N202.1A breast cancer cells resulted in AnnexinV3.18-positive blebbing cells and an increase of Caspase 3/7 acitivity. This further verifies the data from the whole genome expression profiling and indicates that interference with AP-2 proteins sensitizes N202.1A breast cancer cells to apoptosis, which might be one reason for the increase in chemo- and radiation-sensitivity observed upon functional impairment of AP-2 transcriptional activity.

\section{Discussion}

Although single AP-2 proteins have been implicated in tumorigenesis in various types of cancers, their concerted action in initiation and progression of breast cancer is far from being understood. Previous work put its focus on the analysis of the role of single AP-2 isoforms in the etiology of breast cancer. Using a dominant-negative AP-2 mutant, we demonstrated that simultaneous interference with both, AP- $2 \alpha$ and AP- $2 \gamma$ leads to a decrease in proliferation and induction of apoptosis in N202.1A breast cancer cells. 


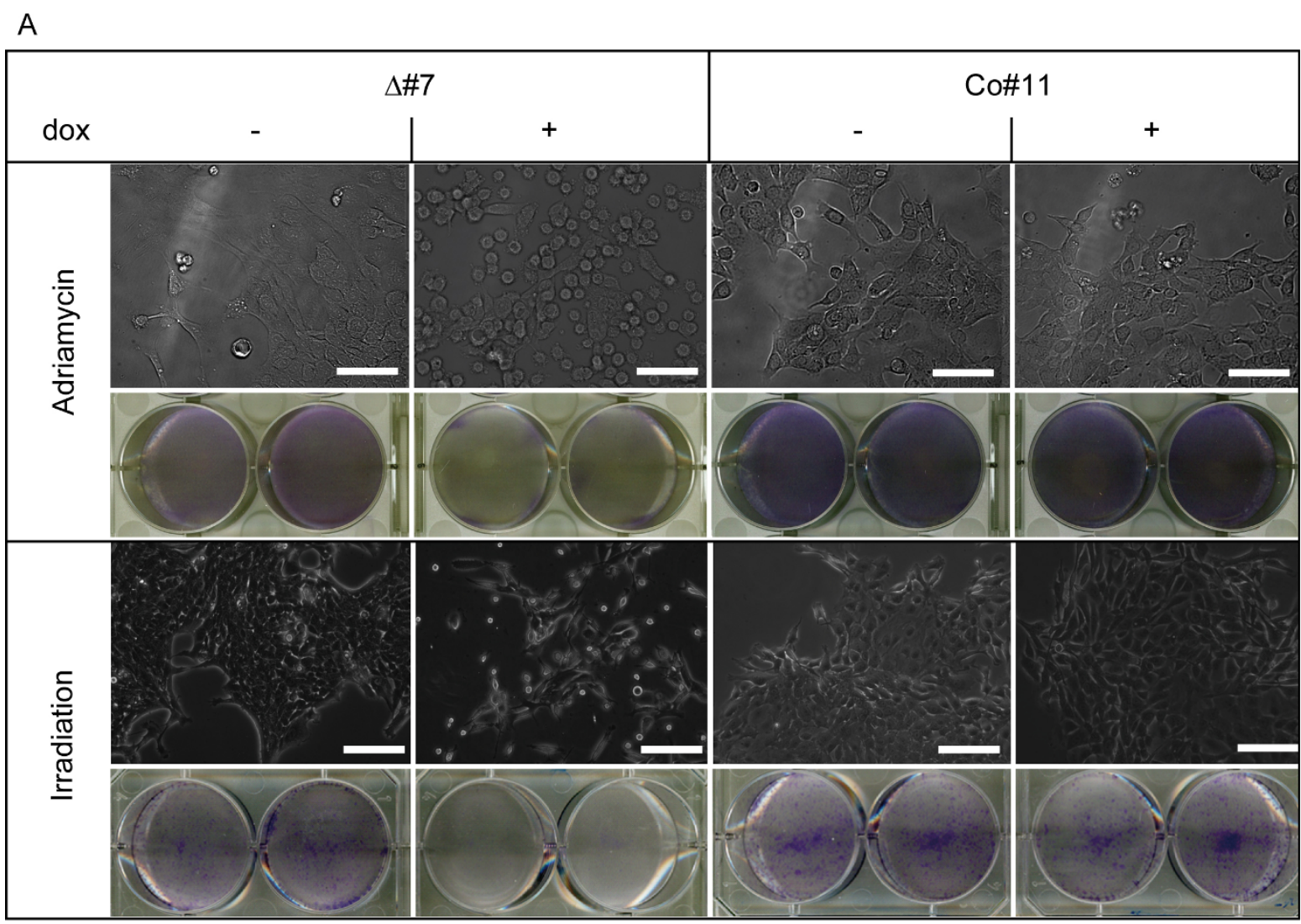

B

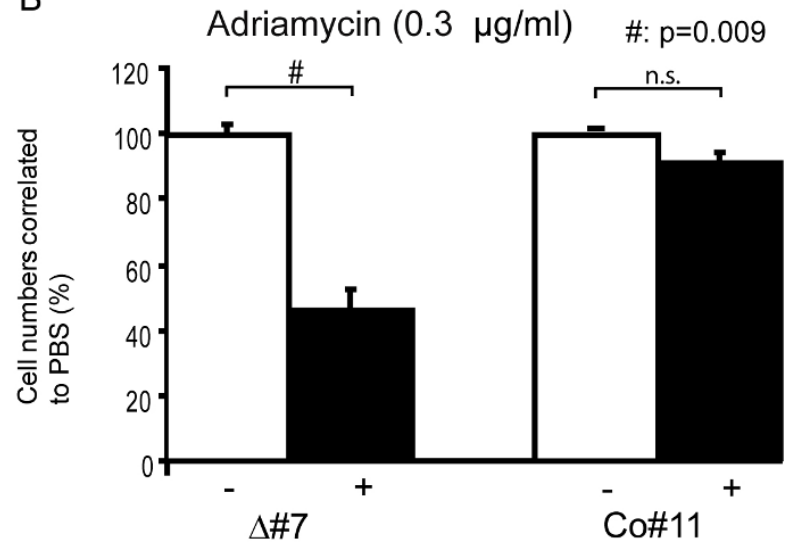

C

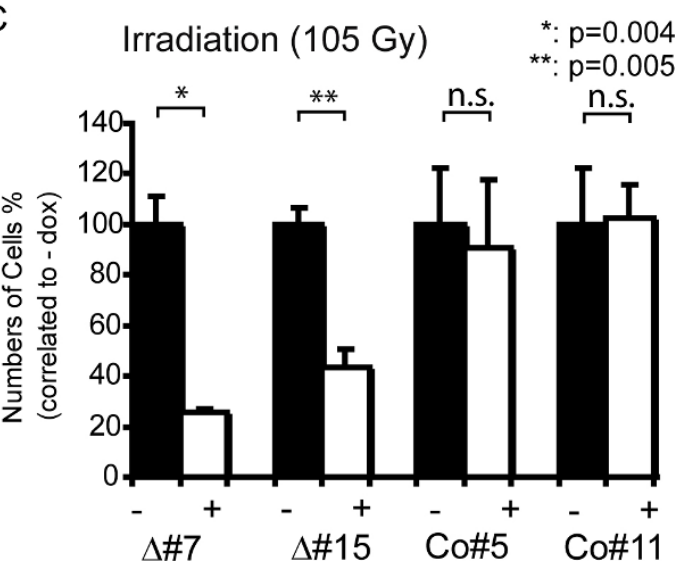

Figure 4 Interference with AP-2 results in an increase in chemo- and radiation-sensitivity in N202.1A breast cancer cells. (A) N202.1A cells were left untreated (-) or induced with doxycycline (+) for $96 \mathrm{~h}$ and then Adriamycin $(0.3 \mu \mathrm{g} / \mathrm{ml})$ was addded for $72 \mathrm{~h}$ (upper columns) or irradiation of 105 Gy was applied (lower columns). Visualisation under the phasecontrast microscope $72 \mathrm{~h}$ after treatment with Adriamycin revealed a significant increase in blebbing and dead cells in $\triangle \# 7$ expressing $\triangle A P-2 \gamma$ (+dox) compared to uninduced (-dox) and Co\#11 cells $(-/+$ dox $)$. A decreased number of cells is also seen using Giemsa staining upon expression of $\triangle \mathrm{AP}-2 \gamma$ in $\triangle \# 7$ (+dox) in comparison to uninduced cells and Co\#5 cells. Phase contrast microscopy $72 \mathrm{~h}$ after irradiation revealed a higher amount of dead cells in $\triangle \# 7$ compared to uninduced and Co\#11 cells ( $/ /+$ dox). Lower amounts of cells are also seen using Giemsa staining upon expression of $\triangle \# 7$ (+dox) in comparison to uninduced cells (-dox) and Co\#11 (-/+dox). Scale Bar represents $50 \mu \mathrm{m}$. (B) Quantification of cell numbers shows a decrease in cell numbers of approximately 50\% following interference with AP-2 proteins $(\triangle \# 7,+$ dox). Cell numbers are normalized to PBS treated controls. P-value of unpaired t-test is given, (n.s. not significant). (C) For determination of radiation-sensitivity the N202.1A clones are induced for $96 \mathrm{~h}$ or left uninduced followed by irradiation with $105 \mathrm{~Gy}$. Normalisation of cell numbers to uninduced controls revealed a significant decrease in cell numbers upon expression of $\triangle A P-2(\triangle \# 7,+; \triangle \# 15,+)$. P-value of unpaired $t$-test is given (n.s. not significant). 

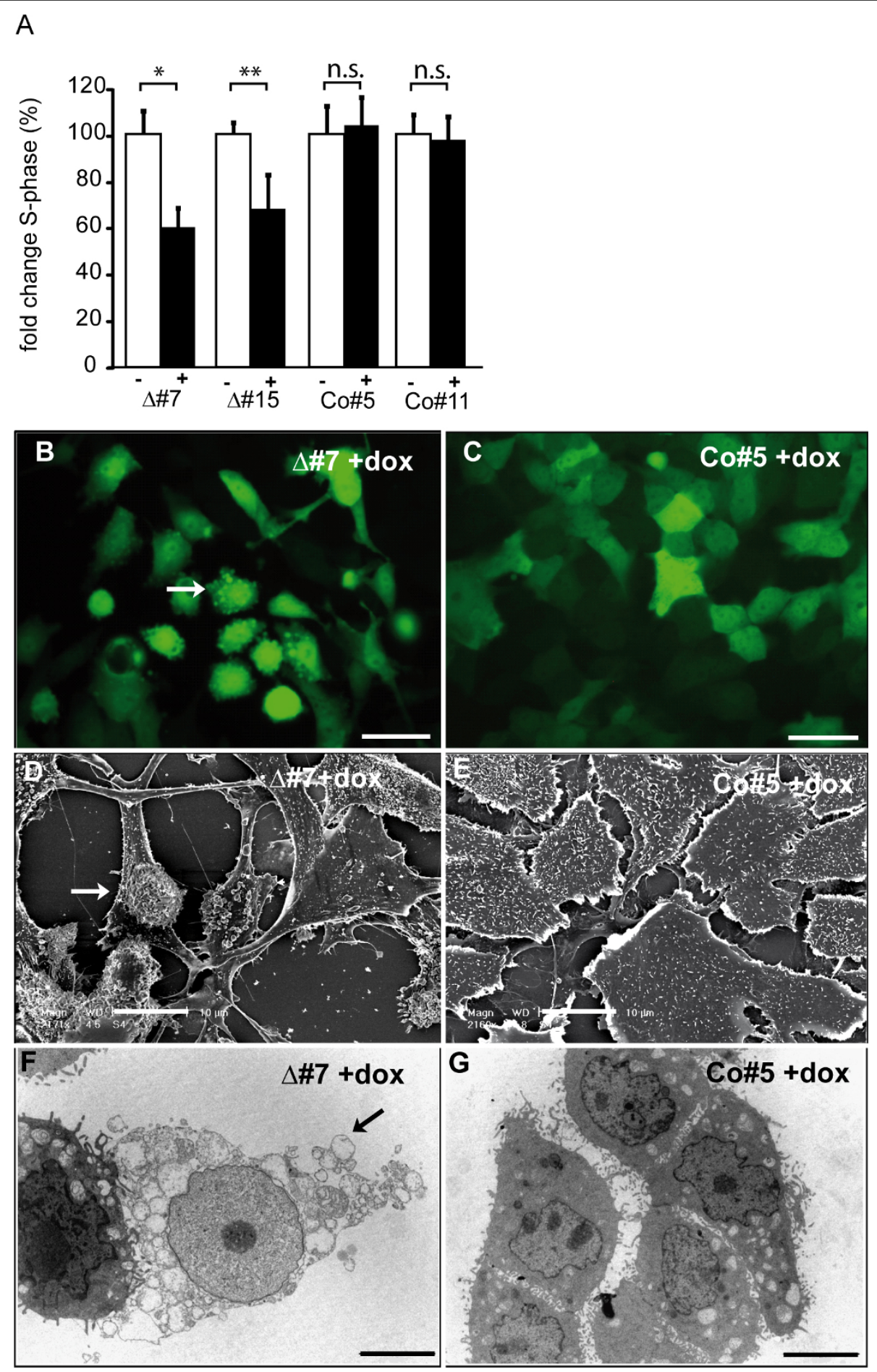

Figure 5 Impairment of proliferation and enhanced apoptosis upon interference with AP-2 proteins in N202.1A breast cancer cells (A) Click-iT Edu assays to determine the amount of cells in S-phase upon expression of $\triangle A P-2 \gamma$ in N202.1A. Induced clones were normalized to uninduced clones and the percentage of cells in S-phase determined. *:P $<0.01$, **:P $<0.05$, n.s.nnot significant. (B, C) N202.1A breast tumor cells were treated with doxycycline for $96 \mathrm{~h}$ and then subjected to fluorescence, SEM (D, E) and TEM ( $F, G)$ analyses. Upon expression of the dominant-negative AP-2 $\gamma$ mutant in N202.1A cells (B, D, F), membrane surface blebbing (indicated by the arrows) can be observed, while control cells display a regular polygonal morphology (C, E, G). Scale Bar represents $20 \mu \mathrm{m}$. 
Furthermore the cells became increasingly sensitive to chemotherapeutic drugs and irradiation.

AP- $2 \alpha$ and AP- $2 \gamma$ were suggested to act as decisive pacemakers for cellular fates such as proliferation, apoptosis and differentiation in the mammary epithelium under physiological conditions $[5,20]$. Therefore, their inappropriate spatio-temporal expression might contribute to malignant transformation. While in the normal breast tissue AP- $2 \alpha$ and AP- $2 \gamma$ show non-overlapping expression patterns [5], coexpression of AP- $2 \alpha$ and AP- $2 \gamma$ was detected in undifferentiated breast carcinomas [4]. There is increasing evidence that the net outcome whether a cell proliferates, undergoes apoptosis or differentiates depends on the balance of various AP-2 proteins [22]. Here, interference with AP-2 proteins using a dominant-negative AP-2 mutant in N202.1A breast cancer cells resulted in a decreased proliferation rate. Remarkably, overexpression of AP- $2 \gamma$ in the mammary gland using a transgenic mouse approach caused an increase in proliferation as well [20], highlighting the notion that certain AP-2 proteins might trigger proliferation.

Wajapeyee et al. correlated increased AP- $2 \alpha$ expression with an enhanced rate of apoptosis after treatment with cytostatic compounds $[7,8]$. Our results, however, suggest that global interference with AP-2 proteins rather sensitizes cells to apoptosis and anticancer treatment regimen. We obtained conflicting results to those reported for the function of AP- $2 \alpha$ alone because we could detect apoptosis and an increased sensitivity towards chemotherapeutic drugs and irradiation after global interference with AP-2 proteins. Our approach benefits from the fact that the dominant-negative AP-2 mutant presumably interferes with all AP-2 homo- and heterodimers present in N202.1A breast cancer cells, which possibly occupy different target gene promoters than AP- $2 \alpha$ alone. While this approach can not distinguish between the functions of individual AP-2 family members, it suggests that

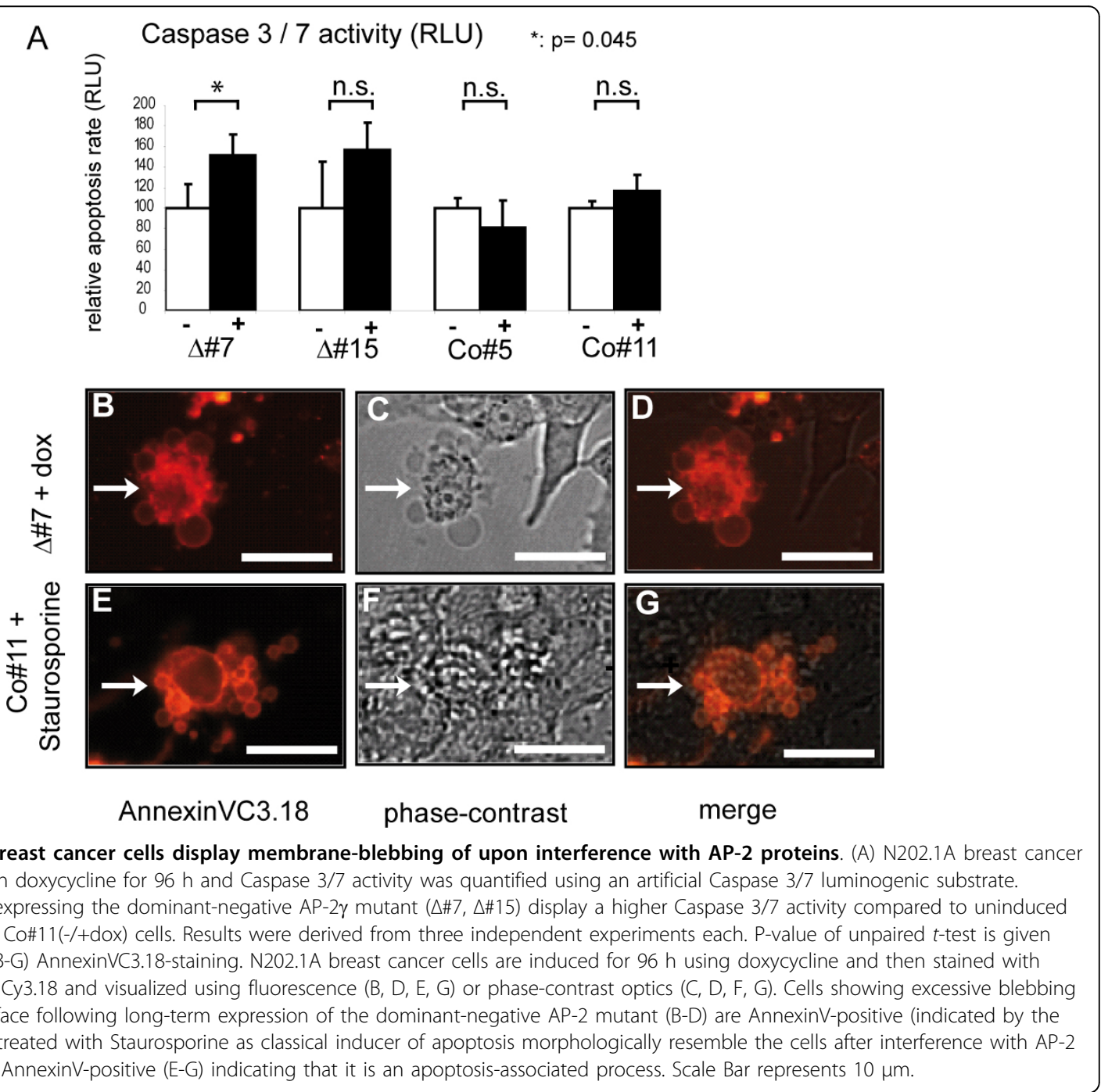


interfering with AP- $2 \gamma$ may sensitize to apoptosis even in the absence of functional AP- $2 \alpha$.

The whole genome expression analysis revealed 139 differentially expressed genes upon interference with AP-2 proteins. Their function might explain the decrease in proliferation rate and at the same time the increase in chemo- and radiation-sensitivity upon repression of AP-2 function also based on modulations of some of these genes previously found following chemical and genetic perturbations [25]. On mRNA level the following genes were found upregulated upon interference with AP-2 function suggesting that AP-2 proteins act as repressors of these genes: Connective Tissue Growth Factor (CTGF) is described to suppress proliferation in breast cancer cells and other tumor entities and induces apoptosis at least in part by activation of caspase-3 [31-33]. Moreover, low expression levels of CTGF in breast cancer patients have been correlated with a poorer clinical outcome [34]. Neuropilin 1 (NRP-1) receptor has been described to be involved in induction of apoptosis in breast cancer cell lines by inhibiting the Akt-signaling pathway $[35,36]$. The tumor suppressor gene Tumor necrosis factor, alpha-induced protein 3 (Tnfaip3) is an inhibititor of the pro-survival activity of NF $\kappa \mathrm{B}$ [37].

Remarkably, the ATP-binding-cassette, subfamilyB (MDR/TAP) member 9/GSTA3 was downregulated upon interference with AP-2 function. It is member of a family, which has been shown to contribute to the Multidrug Resistance (MDR) phenotype [30]. Additionally this efflux transporter family has been reported to detoxify reactive oxygen species (ROS) generated by irradiation, [29] which is a potential mechanism how tumor cells acquire resistance towards irradiation-induced damage. This might represent a mechanism of sensitization of N202.1A breast cancer cells towards chemotherapeutic drugs and irradiation caused by the abrogation of AP-2 function.

According to the analysis using ingenuity software, the AP-2 target genes predominantly cluster to $\mathrm{NF} \kappa \mathrm{B}$, Tp-53, Ras signalling and Calcium signalling. In summary the concerted deregulation of the candidate genes might render cells more susceptible to apoptosis thus resulting in an increased sensitivity towards chemotherapeutic drugs and irradiation. It remains to be elucidated, whether the candidate genes are direct targets of AP-2 transcription factors or are regulated by an indirect secondary mechanism.

\section{Conclusions}

The simultaneous expression of AP-2 transcription factors in breast cancer cells mediates pro-proliferative and anti-apoptotic functions. In addition they contribute to chemo- and radiation resistance of breast cancer cells. Thus, interference with AP-2 function could increase the sensitivity of tumor cells to therapeutic intervention.

Additional file 1: Table S1: Differentially expressed genes in $\triangle \mathrm{AP}-2 \boldsymbol{\gamma} /$ EGFP-expressing N202.1A breast cancer cells. Microarray analysis (Illumina Ref-8 BeadChip) was performed on $\triangle$ AP-2 $\gamma /$ EGFP- $(\Delta \# 7, \triangle \# 15)$ or EGFP- (Co\#5, Co\#11) expressing N202.1 A clones in triplicate and 139 modulated genes were found (49 decreased, 90 increased, see Methods). $\mathrm{FC}=$ Fold change. $p<0.001 ; \mathrm{FC} .+/-1.5$. Functions: more than one Gene Ontology (GO) category was found in some cases. Genes marked in Red display conserved AP-2 binding sites between mouse and human. Numbers and relative location of AP-2 binding site is given (n.d. = not done).

Additional file 2: Table S2: Gene/Gene Set overlap matrix derived by using the datasets deposited in the Molecular Signatures Database. Row (A) and (B) presents the results of 72 genes identified in the screen here in relation to list all the datasets relevant to the analysis (C-V). The spreadsheet (Overlapgenset) identifies the abbreviations used in (C-V). Red boxes indicate overexpression, green boxes indicate downregulation (Yellow - no information deposited).

\section{Acknowledgements}

We thank Cäcilia Hennes and Jörg Bedorf for excellent technical assistance with the SEM and TEM analyses and Professor E. Medico and Dr D.

Cantarella for Illumina microarray data generation and analyses. We thank Dr. Jutta Kirfel for discussing results. We are grateful to P.-L. Lollini for kindly providing N202.1A cells. This work was supported by DFG Grant Scho 503/6 and 503/7 and the Bonner Forum Biomedizin to HS and by Regione Piemonte Ricerca Scientifica Applicata (CIPE2004) to DT. FO is a fellow of the Regione Piemonte. Ingenuity Pathway Analysis Systems: free trial to FO.

\section{Author details}

'Department of Developmental Pathology, Institute of Pathology, University of Bonn, Medical School, Germany. ${ }^{2}$ Molecular Biotechnology Center (MBC) and Department of Oncological Sciences, University of Turin, Via Nizza, 52, 10126 Torino, Italy. ${ }^{3}$ Center for Complex Systems in Molecular Biology and Medicine, University of Turin, Via Acc. Albertina, 13, 10023 Torino, Italy. ${ }^{4}$ Department of Cell Biology, University of Bonn, Germany. ${ }^{5}$ Department of Radiology, University of Bonn, Medical School, Germany. ${ }^{6}$ Division Molecular Genetics, German Cancer Research Center (DKFZ), Heidelberg, Germany. ${ }^{7}$ National Centre for Biomedical Engineering Science, National University of Ireland, Galway, Ireland.

\section{Authors' contributions}

VT constructed the vectors, generated the cells, performed the induction, radiation and chemotheraphy experiments and writing. FO performed array and ChIP-analyses bioinformatics and interpretation, writing and revision. RJ contributed to conception, acquisition of data, interpretation and writing and performed RNA isolation and northern blots. DE contributed to conception and design, bioinformatics, interpretation, writing and revision of data. GK helped with TEM analyses. SS performed co-immunoprecepitation and western-blot. SG helped with the radiation experiments, DT contributed to interpretation, writing and revision, HS contibuted to conception and design, interpretation, writing and revision. All authors read and approved the final manuscript.

Competing interests

The authors declare that they have no competing interests.

Received: 21 July 2009 Accepted: 11 May 2010 Published: 11 May 2010

\section{References}

1. Eckert D, Buhl S, Weber S, Jager R, Schorle H: The AP-2 family of transcription factors. Genome Biol 2005, 6(13):246. 
2. Bosher JM, Totty NF, Hsuan JJ, Williams T, Hurst HC: A family of AP-2 proteins regulates c-erbB-2 expression in mammary carcinoma. Oncogene 1996, 13(8):1701-1707.

3. Pellikainen JM, Kosma VM: Activator protein-2 in carcinogenesis with a special reference to breast cancer-a mini review. Int J Cancer 2007, 120(10):2061-2067.

4. Friedrichs N, Jager R, Paggen E, Rudlowski C, Merkelbach-Bruse S, Schorle H, Buettner R: Distinct spatial expression patterns of AP-2alpha and AP2gamma in non-neoplastic human breast and breast cancer. Mod Pathol 2005, 18(3):431-438.

5. Friedrichs N, Steiner S, Buettner R, Knoepfle G: Immunohistochemical expression patterns of AP2alpha and AP2gamma in the developing fetal human breast. Histopathology 2007, 51(6):814-823.

6. Hilger-Eversheim K, Moser M, Schorle H, Buettner R: Regulatory roles of AP-2 transcription factors in vertebrate development, apoptosis and cellcycle control. Gene 2000, 260(1-2):1-12.

7. Wajapeyee N, Britto R, Ravishankar HM, Somasundaram K: Apoptosis induction by activator protein 2alpha involves transcriptional repression of Bcl-2. J Biol Chem 2006, 281(24):16207-16219.

8. Wajapeyee N, Raut CG, Somasundaram K: Activator protein 2alpha status determines the chemosensitivity of cancer cells: implications in cancer chemotherapy. Cancer Res 2005, 65(19):8628-8634.

9. Zeng YX, Somasundaram K, el-Deiry WS: AP2 inhibits cancer cell growth and activates p21WAF1/CIP1 expression. Nat Genet 1997, 15(1):78-82.

10. Gee JM, Robertson JF, Ellis IO, Nicholson Rl, Hurst HC: Immunohistochemical analysis reveals a tumour suppressor-like role for the transcription factor AP-2 in invasive breast cancer. J Pathol 1999, 189(4):514-520.

11. Piao Z, Lee KS, Kim H, Perucho M, Malkhosyan S: Identification of novel deletion regions on chromosome arms $2 q$ and $6 p$ in breast carcinomas by amplotype analysis. Genes Chromosomes Cancer 2001, 30(2):113-122.

12. Zhang J, Brewer S, Huang J, Williams T: Overexpression of transcription factor AP-2alpha suppresses mammary gland growth and morphogenesis. Dev Biol 2003, 256(1):127-145.

13. McPherson LA, Loktev AV, Weigel RJ: Tumor suppressor activity of AP2alpha mediated through a direct interaction with p53. I Biol Chem 2002, 277(47):45028-45033.

14. Pellikainen MJ, Pekola TT, Ropponen KM, Kataja W, Kellokoski JK, Eskelinen MJ, Kosma VM: p21WAF1 expression in invasive breast cancer and its association with p53, AP-2, cell proliferation, and prognosis. J Clin Pathol 2003, 56(3):214-220.

15. Kallioniemi A, Kallioniemi OP, Piper J, Tanner M, Stokke T, Chen L, Smith HS, Pinkel D, Gray JW, Waldman FM: Detection and mapping of amplified DNA sequences in breast cancer by comparative genomic hybridization. Proc Natl Acad Sci USA 1994, 91(6):2156-2160.

16. Tanner MM, Tirkkonen M, Kallioniemi A, Collins C, Stokke T, Karhu R, Kowbel D, Shadravan F, Hintz M, Kuo WL, et al: Increased copy number at 20 q13 in breast cancer: defining the critical region and exclusion of candidate genes. Cancer Res 1994, 54(16):4257-4260.

17. Gee JM, Eloranta JJ, Ibbitt JC, Robertson JF, Ellis IO, Williams T, Nicholson RI, Hurst HC: Overexpression of TFAP2C in invasive breast cancer correlates with a poorer response to anti-hormone therapy and reduced patient survival. J Pathol 2009, 217(1):32-41.

18. Guler G, lliopoulos D, Guler N, Himmetoglu C, Hayran M, Huebner K: Wwox and Ap2gamma expression levels predict tamoxifen response. Clin Cancer Res 2007, 13(20):6115-6121.

19. Williamson JA, Bosher JM, Skinner A, Sheer D, Williams T, Hurst HC: Chromosomal mapping of the human and mouse homologues of two new members of the AP-2 family of transcription factors. Genomics 1996, 35(1):262-264

20. Jager R, Werling U, Rimpf S, Jacob A, Schorle H: Transcription factor AP2gamma stimulates proliferation and apoptosis and impairs differentiation in a transgenic model. Mol Cancer Res 2003, 1(12):921-929.

21. Jager R, Friedrichs N, Heim I, Buttner R, Schorle H: Dual role of AP2gamma in ErbB-2-induced mammary tumorigenesis. Breast Cancer Res Treat 2005, 90(3):273-280

22. Richardson BD, Cheng YH, Langland RA, Handwerger S: Differential expression of AP-2gamma and AP-2alpha during human trophoblast differentiation. Life Sci 2001, 69(18):2157-2165
23. Bookout AL, Mangelsdorf DJ: Quantitative real-time PCR protocol for analysis of nuclear receptor signaling pathways. Nucl Recept Signal 2003, 1:e012.

24. Chudin E, Kruglyak S, Baker SC, Oeser S, Barker D, McDaniel TK: A model of technical variation of microarray signals. J Comput Biol 2006, 13(4):996-1003.

25. Subramanian A, Tamayo P, Mootha VK, Mukherjee S, Ebert BL, Gillette MA, Paulovich A, Pomeroy SL, Golub TR, Lander ES, et al: Gene set enrichment analysis: a knowledge-based approach for interpreting genome-wide expression profiles. Proc Natl Acad Sci USA 2005, 102(43):15545-15550.

26. Nanni P, Pupa SM, Nicoletti G, De Giovanni C, Landuzzi L, Rossi I, Astolfi A, Ricci C, De Vecchi R, Invernizzi AM, et al: p185(neu) protein is required for tumor and anchorage-independent growth, not for cell proliferation of transgenic mammary carcinoma. Int J Cancer 2000, 87(2):186-194.

27. Williams T, Tjian R: Characterization of a dimerization motif in AP-2 and its function in heterologous DNA-binding proteins. Science 1991, 251(4997):1067-1071.

28. Zhu CH, Domann FE: Dominant negative interference of transcription factor AP-2 causes inhibition of ErbB-3 expression and suppresses malignant cell growth. Breast Cancer Res Treat 2002, 71(1):47-57.

29. Hayes JD, Pulford DJ: The glutathione S-transferase supergene family: regulation of GST and the contribution of the isoenzymes to cancer chemoprotection and drug resistance. Crit Rev Biochem Mol Biol 1995, 30(6):445-600.

30. Petraccia L, Onori P, Sferra R, Lucchetta MC, Liberati G, Grassi M, Gaudio E: [MDR (multidrug resistance) in hepatocarcinoma clinical-therapeutic implications]. Clin Ter 2003, 154(5):325-335.

31. Hishikawa K, Nakaki T, Fujii T: Connective tissue growth factor induces apoptosis via caspase 3 in cultured human aortic smooth muscle cells. Eur J Pharmacol 2000, 392(1-2):19-22.

32. Hishikawa K, Oemar BS, Tanner FC, Nakaki T, Fujii T, Luscher TF: Overexpression of connective tissue growth factor gene induces apoptosis in human aortic smooth muscle cells. Circulation 1999, 100(20):2108-2112

33. Szeto CC, Chow KM, Lai KB, Szeto CY, Kwan BC, Li PK: Connective tissue growth factor is responsible for transforming growth factor-betainduced peritoneal mesothelial cell apoptosis. Nephron Exp Nephrol 2006, 103(4):e166-174

34. Jiang WG, Watkins G, Fodstad O, Douglas-Jones A, Mokbel K, Mansel RE: Differential expression of the CCN family members Cyr61, CTGF and Nov in human breast cancer. Endocr Relat Cancer 2004, 11(4):781-791.

35. Castro-Rivera E, Ran S, Brekken RA, Minna JD: Semaphorin 3B inhibits the phosphatidylinositol 3-kinase/Akt pathway through neuropilin-1 in lung and breast cancer cells. Cancer Res 2008, 68(20):8295-8303.

36. Castro-Rivera E, Ran S, Thorpe P, Minna JD: Semaphorin 3B (SEMA3B) induces apoptosis in lung and breast cancer, whereas VEGF165 antagonizes this effect. Proc Natl Acad Sci USA 2004, 101(31):11432-11437.

37. Chien W, Yin D, Gui D, Mori A, Frank JM, Said J, Kusuanco D, Marchevsky A, McKenna R, Koeffler HP: Suppression of cell proliferation and signaling transduction by connective tissue growth factor in non-small cell lung cancer cells. Mol Cancer Res 2006, 4(8):591-598.

\section{Pre-publication history}

The pre-publication history for this paper can be accessed here: http://www.biomedcentral.com/1471-2407/10/192/prepub

doi:10.1186/1471-2407-10-192

Cite this article as: Thewes et al:: Interference with Activator Protein-2 transcription factors leads to induction of apoptosis and an increase in chemo- and radiation-sensitivity in breast cancer cells. BMC Cancer 2010 10:192. 